\title{
АНАЛИЗ ПРЕДЛОЖЕНИЙ НАСЕЛЕНИЯ ПРИ ОТБОРЕ ПУБЛИЧНЫХ ЦЕЛЕЙ МИНИСТЕРСТВА ТРУДА, ЗАНЯТОСТИ И СОЦИАЛЬНОЙ ЗАЩИТЫ РЕСПУБЛИКИ ТАТАРСТАН НА 2022 ГОД
}

\author{
(c) 2021 Максимова Маргарита Николаевна \\ доктор экономических наук, доцент, \\ декан факультета социальной работы и высшего сестринского образования \\ Казанский государственный медицинский университет, Россия, Казань \\ E-mail: soc90@mail.ru \\ (c) 2021 Мифтахова Марьям Эльбрусовна \\ кандидат экономических наук, старший преподаватель, \\ кафедра экономической теории и социальной работы \\ Казанский государственный медицинский университет, Россия, Казань \\ E-mail: m_miftakhova@list.ru
}

В ходе открытого онлайн-голосования населения по отбору публичных целей Министерства труда, занятости и социальной защиты Республики Татарстан на 2022 год гражданами были предложены свои варианты целей, направленные на развитие системы социальных услуг. Данная статья посвящена анализу этих предложений и комментариев граждан, данных в ходе голосования, в контексте реальной ситуации в отрасли и мер, принимаемых Министерством.

Ключевые слова: Министерство труда, занятости и социальной защиты Республики Татарстан; публичные цели исполнительных органов государственной власти; онлайн-голосование; борьба с бедностью; повышение доходов граждан.

Важность публичного формирования ключевых целей исполнительных органов власти была отмечена Президентом Республики Татарстан Р.Н.Миннихановым в 2017 году в его Послании Государственному Совету Республики Татарстан. Рост активности населения, его инициативности и заинтересованности к тому, что происходит в республике, ставит перед органами власти новые задачи по повышению открытости деятельности и вовлечению жителей в совместную работу. Именно на это направлен проект по публичному формированию целей и задач исполнительных органов государственной власти Республики Татарстан и общественному контролю за их исполнением, участником которого является Министерство труда, занятости и социальной защиты Республики Татарстан. В рамках проекта стоит задача ежегодно определять наиболее важные направления и индикаторы работы Министерства на следующий год, которые формируются с учетом отраслевой стратегии и государственных программ и с привлечением широкой общественности и экспертного сообщества.

Опрос населения явился важным этапом при отборе публичных целей Министерства труда,

занятости и социальной защиты Республики Татарстан (далее - МТЗ и СЗ РТ или Министерство) на 2022 год. В соответствии с постановлением Кабинета Министров Республики Татарстан № 956 от 25.10.2019 «О публичном формировании целей и задач исполнительных органов государственной власти Республики Татарстан и общественном контроле за их исполнением». Проект начался со сбора предложений по наиболее важным публичным целям от членов Общественного совета при Министерстве и экспертов, утвержденных Общественной палатой Республики Татарстан. Поступившие предложения были рассмотрены Общественным советом при Министерстве, в результате были выбраны цели, которые были вынесены на открытое онлайнголосование. Цели затрагивают вопросы занятости населения, социального обслуживания и социальной защиты населения. Опрос населения проходил на сервисе «Опросы жителей» Портала государственных и муниципальных услуг в течение месяца с 8 ноября по 7 декабря. Участниками голосования по публичным целям Министерства стали 8373 человека (для сравнения, в 2020 году - 7942 человека), которые внесли свой вклад в определение самых важных целей 
и задач работы Министерства, 380 человек предложили варианты в разделе «Свой вариант», 551 житель республики оставил комментарии.

На следующем этапе, 12 декабря 2021 года было проведено заседание Общественного Сoвета при Министерстве, посвященное подведению итогов по отбору публичных целей МТ3 и С3 РТ на 2022 год, в котором принимали участие представители Аппарата Президента Республики Татарстан, Общественной палаты Республики Татарстан, члены Общественного Совета при Министерстве, эксперты, принимающие участие в отборе публичных целей, и пред- ставители Министерства (министр, заместители министра, руководители отделов Министерства). Было принято решение определить в качестве публичных пять целей, набравших в голосовании каждая более 33\% голосов (можно было проголосовать за несколько вариантов, см. табл. 1).

Был проведён анализ комментариев и предложений граждан в разделе «Свой вариант». Предложения граждан и комментарии можно разделить на категории, как показано в табл. 2, где также приведены проценты ответов в категории от общего числа (931) комментариев и предложений.

Таблица 1. Результаты онлайн-голосования по публичным целям Министерства труда, занятости и социальной защиты Республики Татарстан на 2022 год

\begin{tabular}{|l|c|}
\hline \multicolumn{1}{|c|}{ Наименование цели } & \% ответов \\
\hline $\begin{array}{l}\text { Борьба с бедностью. Сокращение численности граждан, имеющих доходы ниже прожи- } \\
\text { точного минимума, не менее чем на 25 тыс. человек }\end{array}$ & $67,0 \%$ \\
\hline $\begin{array}{l}\text { Перевод } 17 \text { социльно значимых услуг в электронный вид. Сохранение доли электронных } \\
\text { заявлений на получение услуг на уровне не менее 90\% }\end{array}$ & $39,5 \%$ \\
\hline $\begin{array}{l}\text { Содействие занятости населения. Обеспечение недопущения роста регистрируемой без- } \\
\text { работицы свыше 1\% от численности рабочей силы }\end{array}$ & $38,8 \%$ \\
\hline $\begin{array}{l}\text { Комплексная реабилитация инвалидов, детей-инвалидов. Увеличение охвата услугами } \\
\text { по реабилитации и абилитации в организациях социального обслуживания: детей- } \\
\begin{array}{l}\text { инвалидов с 79\% до 84\% (не менее 8,5 тыс. чел.), инвалидов - с 75\% до 80\% (не менее } \\
7,5 \text { тыс. чел.) }\end{array}\end{array}$ \\
\hline $\begin{array}{l}\text { Обеспечение доставки в медицинские организации на профилактические осмотры и дис- } \\
\text { пансеризацию не менее 15\% граждан старше 65 лет, проживающих в сельской местности } \\
\text { (не менее 24 тыс. чел.), автотранспортом комплексных центров социального обслужива- } \\
\text { ния населения }\end{array}$ & $34,0 \%$ \\
\hline
\end{tabular}

Таблица 2. Распределение по категориям комментариев и предложений граждан

\begin{tabular}{|l|c|c|}
\hline \multicolumn{1}{|c|}{ Категория } & $\begin{array}{c}\text { Количество } \\
\text { ответов } \\
\text { ватегории }\end{array}$ & $\begin{array}{c}\text { \% ответов в ка- } \\
\text { тегории }\end{array}$ \\
\hline Повышение доходов граждан & 261 & $28 \%$ \\
\hline Система социальной защиты Республики Татарстан & 116 & $12,5 \%$ \\
\hline Снижение уровня безработицы & 109 & $11,7 \%$ \\
\hline Не относящиеся к компетенции Министерства & 70 & $7,5 \%$ \\
\hline Предложения по совершенствованию работы Министерства & 49 & $5,3 \%$ \\
\hline Социальная поддержка инвалидов & 45 & $4,8 \%$ \\
\hline $\begin{array}{l}\text { Создание рабочих мест (в приоритете производственная сфера, сель- } \\
\text { ская местность) с высоким уровнем заработной платы }\end{array}$ & 20 & $2,1 \%$ \\
\hline Социальная поддержка граждан старшего возраста & 17 & $1,8 \%$ \\
\hline $\begin{array}{l}\text { Отклики на реформу по изменению пенсионного возраста, уровень } \\
\text { пенсионного обеспечения }\end{array}$ & 11 & $1,2 \%$ \\
\hline $\begin{array}{l}\text { Расширение / разработка мер социальной поддержки отдельных кате- } \\
\text { горий граждан }\end{array}$ & 6 & $0,6 \%$ \\
\hline Эмоциональные отклики & 227 & $24,4 \%$ \\
\hline
\end{tabular}


Несомненно, лидируют вопросы увеличения доходов и оплаты труда населения, усиления контроля государства за условиями труда и соблюдением трудовых прав работников. Рассмотрим распределение ответов в этой категории по темам более подробно - см. табл. 3 (указан также процент от общего числа ответов в данной категории).

Как видно из табл. 3, достаточно много о3вучено комментариев по вопросу повышения размеров МРОТ, прожиточного минимума, повышения заработной платы работникам бюджетной сферы, уменьшения теневой занятости. Необходимо отметить, что МРОТ на территории Российской Федерации устанавливается федеральными законами и с 1 января 2021 года установлен в размере 12792 рубля в месяц, с 1 января 2022 года - 13890 рублей. В Республике Татарстан (РТ) в рамках социального партнерства 30 декабря 2020 года заключено Соглашение между Федерацией профсоюзов РТ, Координационным советом объединений работодателей РТ, Кабинетом Министров РТ об установлении с 1 января 2021 года минимального размера оплаты труда в организациях внебюджетного сектора экономики РТ в размере 15400 рублей в месяц $(93,3 \%$ от стоимости величины минимального потребительского бюджета в целом по РТ за II квартал 2020 года). 24 декабря 2021 года заключено новое соглашение о размере МРОТ 16700 рублей в месяц (93\% от стоимости величины минимального потребительского бюджета в целом по РТ за II квартал 2021 года). Прожи- точный минимум (ПМ) определяется в соответствии с Федеральным законом от 24.10.1997 г. № 134-Ф3 «О прожиточном минимуме в Российской Федерации» и Законом Республики Татарстан от 20.07.2005 г. № 92-3РТ «О порядке определения величины прожиточного минимума на душу населения и по основным социальнодемографическим группам населения Республики Татарстан». С 2021 года величина ПМ на душу населения, в том числе по основных социальнодемографическим группам населения, ежегодно утверждается на год постановлением Правительства Российской Федерации, в Республике Татарстан - постановлением Кабинета Министров Республики Татарстан. Величина прожиточного минимума в РТ на 2022 год в расчете на душу населения утверждена в размере 10756 руб. (рост по сравнению с 2021 годом на 8\%), для трудоспособного населения - 11724 руб. (рост на $10 \%)$, для детей -10433 руб. (рост на $4 \%$ ), для пенсионеров - 9250 руб. (рост на 10\%).

В РТ продолжается работа по обеспечению соблюдения минимального уровня заработной платы и снижению высокого уровня неполной занятости работников. За январь-ноябрь 2021 г. на заседаниях территориальных межведомственных комиссий заслушано 4111 предприятий, из которых 70\% применяют режим неполной занятости. Кроме того, выявлено 583 предприятия, выплачивающие 1831 работнику заработную плату с нарушением требований закона о минимальном размере оплаты труда. По рекомендациям территориальных межведомственных

Таблица 3. Распределение по темам комментариев и предложений граждан в категории «Повышениедоходов граждан»

\begin{tabular}{|l|c|c|}
\hline \multicolumn{1}{|c|}{ Тема в категории «Повышение доходов граждан» } & $\begin{array}{c}\text { Количество } \\
\text { ответов } \\
\text { в теме }\end{array}$ & $\begin{array}{c}\text { \% ответов } \\
\text { в теме }\end{array}$ \\
\hline $\begin{array}{l}\text { Увеличение величины прожиточного минимума, а значит, и всех пособий } \\
\text { и выплат, рассчитываемых на его основе }\end{array}$ & 87 & $33,3 \%$ \\
\hline $\begin{array}{l}\text { Повышение оплаты труда, соблюдение трудовых прав работающих (вы- } \\
\text { числение реальных размеров заработной платы - устранения разрыва } \\
\text { доходов между должностями) }\end{array}$ & 47 & $18 \%$ \\
\hline Увеличение МРОт & 40 & $15,3 \%$ \\
\hline Увеличение размера стипендий учащихся & 35 & $13,4 \%$ \\
\hline $\begin{array}{l}\text { Увеличение оплаты труда бюджетников (младший персонал дошкольных } \\
\text { образовательных учреждений, педагогов, социальных работников, меди- } \\
\text { цинских работников и т.д.) }\end{array}$ & 25 & $9,6 \%$ \\
\hline $\begin{array}{l}\text { Увеличение роли профсоюзов в регулировании трудовых прав работающих } \\
\text { граждан }\end{array}$ & 20 & $7,7 \%$ \\
\hline $\begin{array}{l}\text { Защита прав трудящихся: условия труда, ненормированный рабочий день, } \\
\text { борьба с «серыми заработными платами» и т.д. }\end{array}$ & 7 & $2,7 \%$ \\
\hline
\end{tabular}


комиссий в 553 организациях 1731 работнику доначислено 5918,3 тыс. рублей и произведены налоговые отчисления на сумму 1172,2 тыс. рублей. Работа по регулированию оплаты труда работников бюджетной сферы ведется в рамках реализации Указа Президента Российской Федерации от 7 мая 2012 года № 597 «О мероприятиях по реализации государственной социальной политики». В результате осуществлен переход на окладную систему оплаты труда работников бюджетной сферы. Продолжается работа по сохранению достигнутого соотношения оплаты труда специалистов образования, здравоохранения, культуры, социального обслуживания, других бюджетных сфер со средней заработной платой в Республике Татарстан.

Контроль за соблюдением трудовых прав работников, в том числе по вопросам оплаты и условий труда, рабочего времени и т.д., осуществляется Государственной инспекцией труда в Республике Татарстан, Прокуратурой Республики Татарстан. Вопросы соблюдения законодательства об оплате труда связаны также с надлежащим оформлением трудовых отношений. В РТ с 2015 года ведется работа по легализации неформальной занятости и закреплению на рабочих местах лиц, заключивших трудовые договоры в результате мероприятий по легализации трудовых отношений. По состоянию на 01.12.2021 года заключено 16607 трудовых договоров. Объем НДФЛ за январь-октябрь 2021 года по сравнению с аналогичным периодом 2020 года увеличился на 11,4\% (на 384,6 млн. руб.).
Проанализируем следующую по популярности, как видно из табл. 2 , категорию комментариев и предложений граждан: система социальной защиты РТ. Рассмотрим распределение ответов в этой категории по темам более подробно - cм. табл. 4 (указан также процент от общего числа ответов в данной категории).

Как видно из табл. 4, особое внимание гражданами было уделено предоставлению мер социальной поддержки семей. Всего на меры социальной поддержки семьям с детьми в 2021 году по Министерству предусмотрено 11,2 млрд. рублей - каждый второй рубль от всех средств, выделенных на предоставление мер поддержки всех категорий граждан, из них средства республиканского бюджета - 4,1 млрд. рублей. Меры социальной поддержки семей относятся к категории адресных и предоставляются семьям, имеющим доходы ниже прожиточного минимума на душу населения и имущественную обеспеченность ниже установленного уровня. Среди мер - ежемесячная выплата в связи с рождением (усыновлением) первого ребенка, ежемесячная выплата на ребенка в возрасте от трех до семи лет включительно, ежемесячное пособие на детей в возрасте до 16 лет, выплата на приобретение лекарственных средств в размере 5000 рублей детям в возрасте до 3-х лет, ежемесячное пособие каждому члену семьи с пятью и более детьми и т.д.

Ведется работа и в прочих направлениях, упомянутых в табл. 4. Стратегическими задачами РТ в области социальной защиты населения

Таблица 4. Распределение по темам комментариев и предложений граждан в категории «Система социальной защиты Республики Татарстан»

\begin{tabular}{|c|c|c|}
\hline $\begin{array}{c}\text { Тема в категории «Система социальной защиты } \\
\text { Республики Татарстан» }\end{array}$ & $\begin{array}{l}\text { Количество } \\
\text { ответов } \\
\text { в теме }\end{array}$ & $\begin{array}{l}\text { \% ответов } \\
\text { в теме }\end{array}$ \\
\hline $\begin{array}{l}\text { Меры социальной поддержки семей, увеличение размеров пособий, уделяя } \\
\text { особое внимание: поддержке многодетных детей (изменение законода- } \\
\text { тельства по утрате семьей статуса многодетной при достижении одним } \\
\text { из детей возраста } 18 \text { лет); поддержке матерей-одиночек, в том числе при } \\
\text { нулевом доходе }\end{array}$ & 43 & $37,1 \%$ \\
\hline $\begin{array}{l}\text { Предоставление государственной услуги по назначению ежемесячной } \\
\text { денежной выплаты на проезд пенсионерам }\end{array}$ & 24 & $20,7 \%$ \\
\hline $\begin{array}{l}\text { Реформирование существующей системы социальной защиты населения } \\
\text { в Республике Татарстан }\end{array}$ & 19 & $16,4 \%$ \\
\hline Борьба с бедностью & 18 & $15,5 \%$ \\
\hline $\begin{array}{l}\text { Указывать причины отказа от предоставления мер социальной поддерж- } \\
\text { ки, информирование о необходимости повторной подачи заявления на } \\
\text { выплаты }\end{array}$ & 8 & $6,9 \%$ \\
\hline Развитие проактивного режима назначения мер социальной поддержки & 4 & $3,4 \%$ \\
\hline
\end{tabular}


являются: предоставление мер социальной поддержки наиболее уязвимым группам граждан исходя из критериев нуждаемости и адресности; предоставление услуг в электронном виде. Министерство активно взаимодействует с Всемирным банком, Центром финансов социальной сферы Научно-исследовательского финансового института Министерства финансов Российской Федерации по реформированию и повышению эффективности системы социальной защиты республики. В 2022 году планируется обеспечить переход на предоставление трех региональных мер социальной поддержки в проактивном режиме (в беззаявительном порядке) и охвата не менее $50 \%$ получателей данных мер поддержки, а именно:

- выплата на приобретение лекарственных средств на детей до 3-х лет из семей со среднедушевым доходом ниже ПМ на душу населения в размере 10000 руб. (выплачивается 2 раза в год по 5000 руб.);

- предоставление дополнительной компенсации за детский сад многодетным семьям со среднедушевым доходом ниже ПМ на душу населения в размере $100 \%$ от оплаты за детский сад;

- назначение компенсации расходов на уплату взноса на капитальный ремонт общего имущества в многоквартирном доме одиноко проживающим неработающим собственникам жилых помещений, достигшим возраста 70 лет и старше.

Анализ следующей по популярности, как следует из табл. 2 , категории комментариев и пред- ложений граждан - «Снижение уровня безработицы» - показал следующее распределение ответов в этой категории по темам, см. табл. 5 (указан также процент от общего числа ответов в данной категории).

Как видно из табл. 5, среди внесенных гражданами предложений наиболее распространенными являются предложения, касающиеся содействия занятости отдельных категорий граждан, в том числе молодежи, предпенсионеров, инвалидов, усиления мероприятий по профессиональному переобучению граждан и т.д. В достижении трудоустройства данных категорий имеются объективные препятствия, связанные с физиологическими, социальными особенностями данной категории. На это направлены мероприятия активной политики занятости и предлагаются меры стимулирования работодателей для принятия на работу. Достаточное количество комментариев касаются вопроса размера пособий по безработице. Размеры минимальной и максимальной величин пособия по безработице ежегодно определяются Правительством Российской Федерации. В 2021 году были установлены: минимальная величина пособия по безработице - 1500 рублей, максимальная величина пособия по безработице - 12130 рублей - в первые три месяца периода безработицы, 5000 рублей - в следующие три месяца периода безработицы. На 2022 год минимальная величина пособия по безработице не меняется (1500 рублей), максимальная величина - 12792 рублей - в первые три месяца периода безработицы.

Таблица 5. Распределение по темам комментариев и предложений граждан в категории «Снижение уровня безработицы»

\begin{tabular}{|c|c|c|}
\hline Тема в категории «Снижение уровня безработицы» & $\begin{array}{l}\text { Количество } \\
\text { ответов } \\
\text { в теме }\end{array}$ & $\begin{array}{c}\text { \% ответов } \\
\text { в теме }\end{array}$ \\
\hline $\begin{array}{l}\text { Усиление поддержки по трудоустройству инвалидов, начинающих пред- } \\
\text { принимателей, молодежи, граждан предпенсионного возраста, выпускни- } \\
\text { ков образовательных организаций (оплачиваемая практика, трудоустрой- } \\
\text { ство в бюджетные организации для получения опыта работы) }\end{array}$ & 42 & $38,5 \%$ \\
\hline Увеличение размера пособия по безработице & 26 & $23,8 \%$ \\
\hline $\begin{array}{l}\text { Организация профессионального обучения безработных граждан, женщин, } \\
\text { имеющих детей дошкольного возраста, граждан 50+ (расширение перечня } \\
\text { профессий, возможность прохождения нескольких смежных профессий, } \\
\text { изменение порядка заключения контрактов / договоров с образовательны- } \\
\text { ми организациями, акцент на обучение в дистанционной форме) }\end{array}$ & 25 & $22,9 \%$ \\
\hline $\begin{array}{l}\text { Увеличение предоставляемых через органы службы занятости населения } \\
\text { вакансий с высоким уровнем заработной платы (25 тыс. и более) }\end{array}$ & 8 & $7,3 \%$ \\
\hline Изменение работы органов службы занятости населения & 4 & $3,7 \%$ \\
\hline $\begin{array}{l}\text { Усиление информационной кампании по программам обучения, услугам } \\
\text { органов службы занятости населения }\end{array}$ & 4 & $3,7 \%$ \\
\hline
\end{tabular}


По замечанию граждан о низкой заработной плате предоставляемых центрами занятости вакансий необходимо отметить, что заявленное работодателями РТ число вакансий на 01.12.2021 г. составило 60,9 тыс. единиц по 1560 различным профессиям (специальностям), из них 65,8\% профессий (специальностей) с заработной платой 25 тыс. рублей и более. Органами службы занятости населения ведется широкая информационная работа с целью повышения имиджа службы занятости. Применяются такие способы информирования, как: СМИ, Интернет, социальные сети, личные встречи, - освещаются истории граждан и работодателей, имеющих результативный опыт взаимодействия со службой занятости. Министерством реализуются мероприятия по обучению как незанятых, так и отдельных категорий занятых граждан. Министерством были проанализированы предложения граждан по совершенствованию работы органов службы занятости, например, изменение подхода к поиску вакансий и предложений для безработных, необходимость усиления информационной кампании о деятельности и услугах центров занятости населения и др. Это важный отклик населения о работе учреждений. Министерство и подведомственные учреждения постоянно совершенствует процесс оказания услуг органами службы занятости. Процесс совершенствования деятельности центров занятости населения на уровне Российской Федерации с 2021 года связан с Порталом «Работа России», который стал платформой для внедрения инноваций. С 2019 года Министерство реализует мероприятия по совершенствованию деятельности службы занятости путем внедрения новых требований к работе центров занятости населения. Созданы кадровые центры «Работа России» на базе центров занятости населения г. Набережные Челны, г. Альметьевска и Московского района г. Казани. На базе кадровых центров разработаны 6 комплексных услуг для социально незащищенных граждан, оказавшихся в трудной жизненной ситуации: «Содействие занятости гражданам I, II, III группы инвалидности», «Содействие занятости женщинам из малоимущих семей, имеющих несовершеннолетних детей, а также малоимущим гражданам пенсионного возраста», «Граждане, освобожденные из учреждений, исполняющих наказание в виде лишения свободы», «Молодые специалисты», «Граждане, возобновляющие трудовую деятельность после длительного перерыва», «Студенты очной формы обучения» и 6 бизнес-ситуаций по взаимодействию с работодателями: «Инвестиционный проект», «Создание малого предприятия», «Комплектование кадрового состава организации», «Содействие кадровому обеспечению предприятий с сезонной занятостью», «Крупный бизнес при дефиците кадров», «Взаимодействие службы занятости с предприятиями при высокой текучести кадров». В настоящее время комплексные услуги апробируются в городах, в дальнейшем они будут распространяться по всей республике.

По поводу предложений по усилению направления «Создание рабочих мест с высоким уровнем заработной платы» (выделенного в табл. 2 в отдельную категорию предложений) следует отметить, что Министерство участвует в поддержке реализации инвестиционных проектов, создания новых предприятий путем подбора и подготовки кадров. В рамках территориальных программ содействия занятости ведется учет предполагаемых к созданию рабочих мест на территории муниципальных районов.

Обратимся теперь к следующим категориям предложений и комментариев граждан: «Социальная поддержка инвалидов» и «Социальная поддержка граждан старшего возраста» (см. табл. 2). Рассмотрим распределение ответов в этих категориях по темам подробнее (см. табл. 6 и табл. 7), соответственно указан также процент от общего числа ответов в данной категории.

Как видно из табл. 6 и табл. 7, гражданами внесены предложения, касающиеся расширения перечня услуг, обеспечения доступной среды для маломобильных групп населения, открытия реабилитационных центров, развития комплексных проектов организаций социального обслуживания и медицинских организаций. В Татарстане функционируют 6 центров реабилитации инвалидов, 6 социально-реабилитационных отделений комплексных центров социального обслуживания населения, 12 негосударственных организаций, оказывающих реабилитационные услуги гражданам пожилого возраста и инвалидам по межтерриториальному принципу. В соответствии с установленным уровнем социальных гарантий в республике отмечается полная обеспеченность данными учреждениями. Ежегодно порядка 18 тыс. инвалидов и детей-инвалидов получают социальные реабилитационные услуги с целью улучшения качества жизни, со- 
Таблиц̧а 6. Распределение по темам комментариев и предложений граждан в категории «Социальная поддержка инвалидов»

\begin{tabular}{|l|c|c|}
\hline \multicolumn{1}{|c|}{ Тема в категории «Социальная поддержка инвалидов» } & $\begin{array}{c}\text { Количество } \\
\text { ответов } \\
\text { в теме }\end{array}$ & $\begin{array}{c}\text { \% ответов } \\
\text { в теме }\end{array}$ \\
\hline $\begin{array}{l}\text { Расширение предоставляемых мер социальной поддержки, в т.ч. в проак- } \\
\text { тивном режиме }\end{array}$ & 15 & $33,3 \%$ \\
\hline $\begin{array}{l}\text { Расширение перечня услуг инвалидам, в т.ч. такси для инвалидов, особен- } \\
\text { но в сельской местности }\end{array}$ & 9 & $20 \%$ \\
\hline Доступная среда для маломобильных групп населения & 6 & $13,3 \%$ \\
\hline Открытие реабилитационных центров для граждан 18+ & 4 & $8,9 \%$ \\
\hline $\begin{array}{l}\text { Предоставление медицинской помощи, выдача технических средств реа- } \\
\text { тенцици Министерства) }\end{array}$ & 8 & $17,8 \%$ \\
\hline $\begin{array}{l}\text { Инклюзивное образование, обеспечение кадрами работу с детьми- } \\
\text { инвалидами в образовательных организациях (не в компетенции Мини- } \\
\text { стерства) }\end{array}$ & 3 & $6,7 \%$ \\
\hline
\end{tabular}

Таблица 7. Распределение по темам комментариев и предложений граждан в категории «Социальная поддержка граждан старшего возраста»

\begin{tabular}{|l|c|c|}
\hline \multicolumn{1}{|c|}{ «Сециальная поддержка граждан старшего возраста» } & $\begin{array}{c}\text { Количество } \\
\text { ответов } \\
\text { в теме }\end{array}$ & $\begin{array}{c}\text { \% ответов } \\
\text { в теме }\end{array}$ \\
\hline Развитие услуг социального обслуживания для граждан старшего возраста & 12 & $70,6 \%$ \\
\hline $\begin{array}{l}\text { Создание реабилитационных центров для граждан старшего возраста, ор- } \\
\text { ганизация дневной занятости, в т.ч. по обучению основам компьютерной } \\
\text { грамотности }\end{array}$ & 3 & $17,6 \%$ \\
\hline Развитие профориентационной работы среди граждан старшего возраста & 1 & $5,9 \%$ \\
\hline $\begin{array}{l}\text { Развитие комплексных проектов организаций социального обслуживания } \\
\text { и медицинских организаций }\end{array}$ & 1 & $5,9 \%$ \\
\hline
\end{tabular}

хранения работоспособности и интеграции их в общество. В реабилитационных центрах организована система комплексной реабилитации или абилитации, ранней помощи, направленная на профилактику детской инвалидности, улучшение состояния здоровья, повышение качества жизни граждан и их семей.

Несколько комментариев было посвящено развитию службы такси для инвалидов. В республике развитие услуги социального такси осуществляется в рамках конкурсных механизмов поддержки социально ориентированных некоммерческих организаций через участие их в конкурсах социальных проектов, направленных на решение социальных проблем населения, например, Региональная общественная организация инвалидов «Интеграция», Региональная общественная организация родителей детейинвалидов Республики Татарстан «Забота». Услуги социального такси предоставляются также в наиболее крупных муниципальных районах и городах РТ автотранспортными предприятиями за счет средств, выделяемых из местного бюджета. В рамках реализации государственной программы Российской Федерации «Доступная среда» в Республике Татарстан с 2011 года на реализацию программы «Доступная среда» направлено 2,7 млрд. рублей, за 10 лет адаптирован 921 объект в приоритетных сферах жизнедеятельности инвалидов (здравоохранение, социальная защита и занятость населения, культура, физическая культура и спорт, образование). В текущем году на 86 объектах социальной сферы будут проведены адаптационные работы на общую сумму 114 млн. рублей.

Таким образом, можно заключить, как показывают результаты голосования, население республики волнуют вопросы борьбы с бедностью, предоставления услуг в электронном виде, недопущения роста безработицы, комплексной реабилитации инвалидов, доставки в медицинские организации на профилактические осмот- 
ры и диспансеризацию, заработной платы социальных работников, трудоустройства граждан, обратившихся в органы службы занятости.

Предложенные гражданами собственные варианты целей говорят о неравнодушии граждан, о желании совершенствовать работу отрасли, о высокой степени вовлеченности населения в проект и его активном участии в жизни государства. Все задачи, которые были представлены для голосования, останутся в поле зрения Министерства. О реализации выбранных целей будут предоставляться отчеты, которые будут размещены в общем доступе на сайте Министерства и официальном сайте проекта «Публичное формирование целей и задач исполнительных органов государственной власти и общественный контроль за их исполнением».

\section{Библиографический список}

1. Официальный сайт Министерства труда, занятости и социальной защиты Республики Татарстан [Электронный ресурс] // Информационно-правовой портал. URL: http://www.mtsz.tatarstan.ru (дата обращения: 31.11.2021).

2. Перечень поручений Президента Российской Федерации по итогам встречи с социальными работниками и представителями некоммерческих организаций от 24.06.2021 № Пр-1093 [Электронный ресурс] // СПС КонсультантПлюс. URL: http://www.consultant.ru/document/cons_doc_LAW_ 388312 (дата обращения: 31.11.2021).

3. Проект «Публичное формирование целей и задач исполнительных органов государственной власти и общественный контроль за их исполнением» [Электронный ресурс] // Официальный портал. URL: http://publictasks.tatarstan.ru (дата обращения: 31.11.2021). 